\title{
Kontaktallergi mot hennatatovering
}

\author{
Sammendrag \\ Bakgrunn. Tatoveringer med farge- \\ stoffet henna er blitt svært populære, \\ og forekomsten av kontaktallergi synes \\ å øke.
}

Materiale og metode. Dette er en kort oversiktsartikkel basert på materiale funnet ved søk i PubMed med søkeordene «henna», «paraphenylendiamin» og «allergic contact dermatitis» samt egne kliniske erfaringer. Tilstanden illustreres ved en kasuistikk.

Resultater. Det er godt dokumentert at mange får reaksjon i huden etter hennatatovering. Dette skyldes nesten alltid kontaktallergi overfor azofargestoffet parafenylendiamin, som er tilsatt for at fargeprosessen skal gå hurtigere og fargen bli mørkere. De fleste hennatatoveringer utføres under feriereiser i Asia eller i middelhavsområdet, også hos mange barn. Etablert kontaktallergi er varig. Mange hårfargemidler inneholder parafenylendiamin, og personer med kontaktallergi mot stoffet kan ved bruk av slike midler utvikle et svært kraftig kontaktallergisk eksem. Akutte reaksjoner behandles med lokale kortisonpreparater, eventuelt med systemiske steroider. Kryssreaksjon overfor stoffer med liknende kjemisk struktur kan forekomme.

Konklusjon. Tatoveringer med hennapulver som inneholder parafenylendiamin frarådes.

\author{
Bjarte Steinkjer \\ stbj@sus.no \\ Katarina Zak Stangeland \\ Carsten Sauer Mikkelsen* \\ Hudavdelingen \\ Stavanger universitetssykehus \\ Postboks 8100 \\ 4068 Stavanger
}

* Nåværende adresse:
Bredegade 13, 2. sal
9700 Brønderslev
Danmark

Hennatatoveringer er blitt svært populære, og det kan synes som om forekomsten av kontaktallergi øker. Vi har hatt flere pasienter med slike plager og vil gjerne gi en kort oversikt over fenomenet for at allmennleger og hudleger skal kunne stille riktig diagnose og gi adekvate råd til sine pasienter.

\section{Materiale og metode}

Denne oversikten er basert på flere artikler funnet ved ikke-systematiske søk i PubMed med søkeordene «henna», «paraphenylendiamin» og «allergic contact dermatitis». Dessuten bygger den på egne kliniske erfaringer. Tilstanden illustreres ved en kasuistikk (ramme 1, fig 1, fig 2).

\section{Hennaplanten}

Henna er det arabiske navnet på en busk som på latin heter Lawsonia inermis. Den vokser i tempererte områder i Asia og Nord-Afrika. Hennabusken ble katalogisert av Linné og fikk navn etter hans assistent Isaac Lawson. Bladene tørkes og knuses til et pulver som blandes med olje eller vann til en pasta. Denne gir etter kontakt med huden pigmentering, og fargestyrken øker med virketiden. Temperatur og luftfuktighet har også betydning for pigmenteringsprosessen. Den aktive ingrediensen $i$ henna er lawsone (2-hydoksy1,4-naftokinon). Fargestoffet bindes til hudens keratin, men pigmenteringen forsvinner gradvis når huden fornyes $(1,2)$.

Henna er blitt brukt til kroppsdekorasjon i flere tusen år, i både religiøs og estetisk hensikt $(2,3)$. Denne tradisjonelle bruken av henna tolereres godt. Det er få rapporter om allergi overfor henna, selv i land der produktet er blitt brukt i generasjoner (3). Problemer med kontaktallergi synes først å ha oppstått etter at andre tilsetningsstoffer, spesielt parafenylendiamin (PPD), er blitt tilført det opprinnelige hennaproduktet $(1,2)$.

\section{Parafenylendiamin}

Parafenylendiamin er et oksiderende intermediat i syntesen av azofargestoffer. Det finnes hovedsakelig i hårfargemidler og mørke, syntetiske tekstiler, men kan også påvises i gummiprodukter, plastprodukter, trykksverte, skofarger, kosmetikk, fotokopieringsvæsker og oljeprodukter (4).

Fargestoffet blir tilsatt hennapulveret for at hennatatoveringene skal kunne gjennomføres hurtigere og pigmenteringen bli mørkere og mer varig. Produktet kalles gjerne svart henna og er beregnet for travle turister, gjerne fra vestlige land $(1,2)$. Parafenylendiamin er påvist $i$ hennatatoveringer $i$ varierende konsentrasjoner, oftest $\mathrm{i}$ området 0,25-2,35 \% (5), men også i så høy konsentrasjon som $15 \%$ (6). I EU er høyeste tillatte konsentrasjon av parafenylendiamin i hårfargemidler fastsatt til $6 \%$ (2). Ved høyere konsentrasjoner vil mange som utsettes for produktet bli sensibilisert (7).

\section{Kontaktallergi}

Kontaktallergi overfor parafenylendiamin ses relativt ofte. Stoffet inngår i standardiserte tester som hudleger benytter ved utredning av pasienter der det er mistanke om kontaktallergisk eksem.

De som er allergiske overfor parafenylendiamin, kan få svært kraftige reaksjoner dersom de benytter hårfargemidler som inneholder stoffet (7). Vi har sett pasienter som er blitt innlagt i medisinsk avdeling pga. mistanke om hudinfeksjon, men der årsaken har vært kontaktallergi etter hårfarging. Tiltak er da behandling med lokale kortisonpreparater, ev. også systemisk kortisonbehandling.

Hennatatovering er spesielt populært blant barn og unge. Vår pasienthistorie er et typisk eksempel (ramme 1). Sensibilisering kan oppstå etter første eksposisjon når konsentrasjonen er høy. Synlig reaksjon i huden (eksem) oppstår vanligvis etter 1-3 uker,

\section{Hovedbudskap}

- Fargestoffet parafenylendiamin tilsettes ofte hennapulver beregnet på tatovering og kan gi kontaktallergi

- Parafenylendiamin finnes også i hårfargemidler og mørke tekstilfargestoffer

- Hårfarging med parafenylendiamin kan gi svært kraftige kontaktallergiske reaksjoner 


\section{Ramme 1}

\section{En pasient med kontaktallergi mot hennatatovering}

En seks år gammel gutt fikk en hennatatovering på høyre arm da han var på ferie i Tyrkia. Etter 1-2 uker oppsto det kløe, rødme og hevelse på tatoveringsstedet. Han ble behandlet med kortisonkrem av sin fastlege. Etter tre uker ble gutten undersøkt ved en hudavdeling. Det ble da funnet en erytematøs, vœskende lesjon på tatoveringsstedet (fig 1). På huden rundt var det et makulopapuløst eksantem. Det ble gitt behandling med gruppe IIIkortikosteroidkrem (mometasonfuroat).

Gutten ble testutredet etter noen måneder. Først ble parafenylendiamin 1 \% i vaselin lagt på huden som en åpen test. Det var ingen reaksjon etter 30 minutter. Deretter ble det lagt en vanlig epikutantest (lappetest), der parafenylendiamin ble fortynnet til $25 \%$ av vanlig testkonsentrasjon. Vanligvis tas testsubstansene av etter 48 timer, men foreldrene fikk beskjed om å fjerne testlappene tidligere ved tegn til reaksjon. Dette ble gjort etter 24 timer. Ved avlesing etter 72 timer var det en kraftig reaksjon (fig 2).

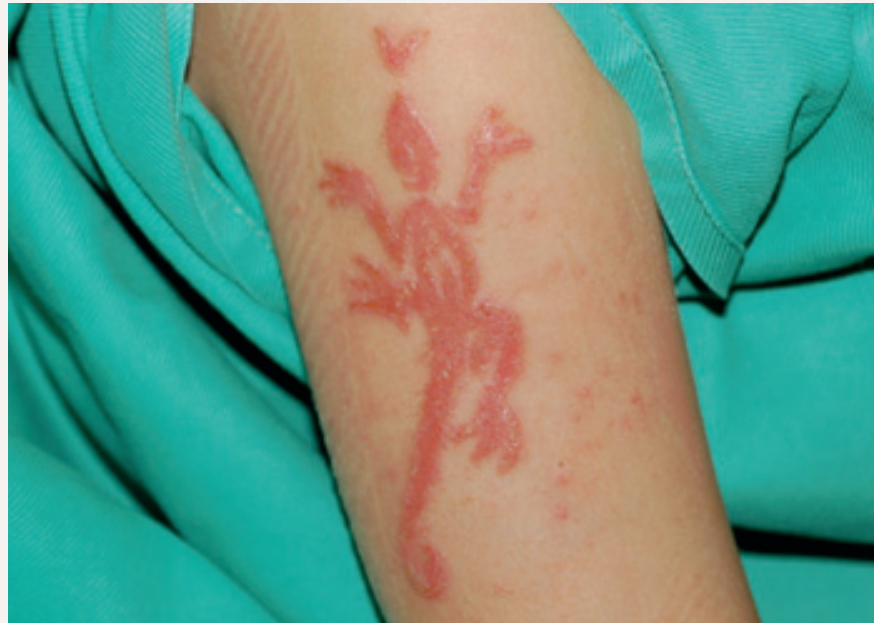

Figur 1 Reaksjon etter hennatatovering

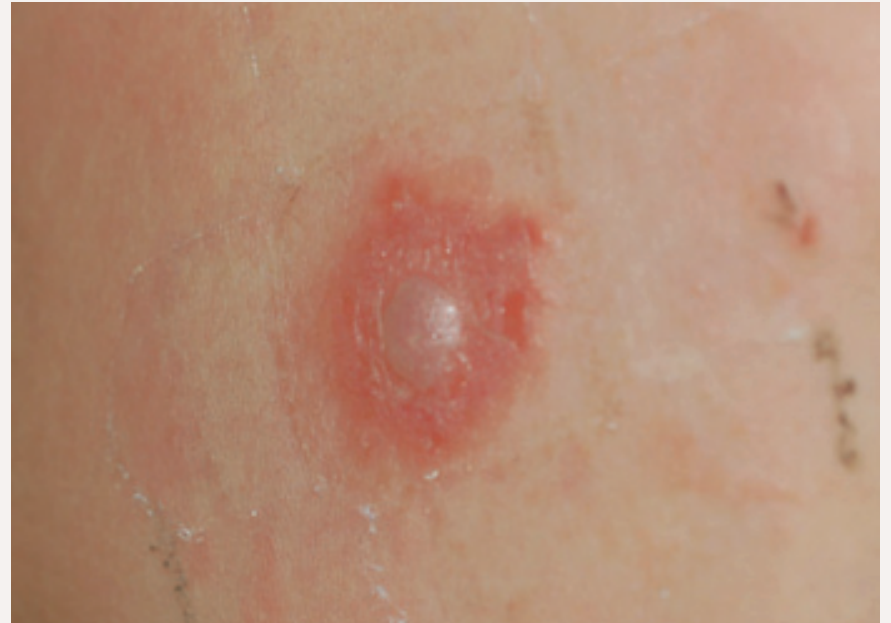

Figur 2 Positiv testreaksjon på parafenyldiamin noe som betyr at utslettet ofte først manifesterer seg etter at ferieoppholdet er over. Ved tidligere sensibilisering vil mer akutte reaksjoner kunne oppstå. Sensibilisering medfører livslang allergi overfor fargestoffet.

Pasienter der det er mistanke om kontaktallergi, skal henvises til hudlege. På grunn av risikoen for kraftige reaksjoner bør testutredning foretas med fortynnet testmateriale, og applikasjonstiden bør også forkortes (8).

Langvarig hyperpigmentering eller depigmentering av huden etter allergireaksjonen kan ses $(9,10)$. Mer sjelden er lichenoide reaksjoner (1) og erythema multiforme-liknende utslett (10).

De som er allergiske overfor parafenylendiamin, vil aldri kunne farge hår og skjegg eller benytte andre kosmetiske produkter som inneholder substansen. Bruk av mørke syntetiske tekstiler kan også medføre problemer.

Kontaktallergi mot parafenylendiamin kan gi kryssreaksjon overfor kjemisk beslektede stoffer, særlig andre tekstilfargestoffer $(11,12)$ og kurvplanteallergenet seskviterpenlakton (13). Det er også rapporter om mulig kryssreaksjon med enkelte medikamenter, som mesalazin (14), sulfonamid (15) og hydroklortiasid (16), men slike kryssreaksjoner synes å være dårligere dokumentert.

\section{Diskusjon}

Vi har de siste årene hatt flere pasienter som har utviklet kontaktallergi mot parafenylen- diamin etter å ha fått utført hennatatovering, og forekomsten synes å være økende. Kontaktallergi mot hennatatovering kan medføre betydelige problemer for pasientene. Leger som arbeider i primærhelsetjenesten og ved sykehusavdelinger bør kjenne til muligheten for denne formen for kontaktallergi og dens kliniske manifestasjoner, blant annet kraftig hodebunnsreaksjoner etter hårfarging. Vi har også en informasjonsoppgave overfor befolkningen.

\section{Oppgitte interessekonflikter: Ingen}

\section{Litteratur}

1. Wolf $\mathrm{R}$, Wolf $\mathrm{D}, \mathrm{Matz} \mathrm{H}$ et al. Cutaneous reactions to temporary tattoos. Dermatol Online J 2003; 9: 3 . 2. Calogiuri G, Foti C, Bonamonte D et al. Allergic reactions to henna-based temporary tattoos and their components. Immunopharmacol Immunotoxicol 2010; 32: 700-4.

3. Natow AJ. Henna. Cutis 1986; 38: 21

4. Chemotechnique Diagnostics. Patch test products. www.chemotechnique.se/Catalogue.htm (11.2.2011).

5. Kang IJ, Lee MH. Quantification of para-phenylenediamine and heavy metals in henna dye. Contact Dermatisis 2006; 55: 26-9.

6. Brancaccio RR, Brown LH, Chang YT et al. Identification and quantification of para-phenylenediamine in a temporary black henna tattoo. Am J Contact Dermat 2002; 13: 15-8.

7. Sosted H, Johansen JD, Andersen KE et al. Severe allergic hair dye reactions in 8 children. Contact Dermatitis 2006; 54: 87-91.

8. Ho SGY, White IR, Rycroft RJG et al. A new approach to patch testing patients with paraphenylenediamine allergy secondary to temporary black henna tattoos. Contact Dermatitis 2004; 51: $213-4$.
9. Valsecchi R, Leghissa P, Di Landro A et al. Persis tent leukoderma after henna tattoo. Contact Dermatitis 2007; 56: 108-9.

10. Jappe U, Hausen BM, Petzoldt D. Erythema-multiforme-like eruption and depigmentation following allergic contact dermatitis from a paint-on henna tattoo, due to para-phenylenediamine contact hypersensitivity. Contact Dermatitis 2001; 45: 249-50.

11. Goon AT, Gilmour NJ, Basketter DA et al. High frequency of simultaneous sensitivity to Disperse Orange 3 in patients with positive patch test to para-phenylenediamine. Contact Dermatitis 2003, 48: $248-50$

12. Kiec-Swierczynska M, Krecisz B, SwierczynskaMachura D. Allergy to p-phenylenediamine from a black transferable picture tattoo - hypopigmentation and sensitization to clothing dyes in a little girl. Contact Dermatitis 2008; 58: 174-5

13. Paulsen E, Christensen LP. Andersen KE. Possible crossreaction between para-phenylenediamine and sesquiterpene lactones. Contact Dermatitis 2008: 58: $120-2$

14. Charles J, Bourrain JL, Tessier A et al. Mesalazine and para-phenylenediamine allergy. Contact Dermatitis 2004; 51: 313-4.

15. Arroyo MP. Black henna tattoo reaction in a person with sulfonamide and benzocaine drug allergies. J Am Acad Dermatol 2003; 48: 301-2.

16. Jacob SE, Zapolanski T, Chayavichitsilp P. Sensitivity to para-phenylenediamine and intolerance to hydrochlorothiazide. Dermatitis 2008; 19: E44-5.

Pasientens pårørende har gitt samtykke til at artikkelen blir publisert.

Manuskriptet ble mottatt 20.10. 2010 og godkjent 20.1. 2011. Medisinsk redaktør Petter Gjersvik. 